\title{
New Mechatronics Education Initiatives
}

\section{Dr. Marilyn Barger, National Science Foundation ATE Centers}

Dr. Marilyn Barger is the Principal Investigator and Executive Director of FLATE, the Florida Regional Center of Excellence for Advanced Technological Education, funded by the National Science Foundation and housed at Hillsborough Community College in Tampa, Florida since 2004. FLATE serves the state of Florida as its region and is involved in outreach and recruitment of students into technical career pathways; has produced award winning curriculum design and reform for secondary and post-secondary Career and Technical Education programs; and provides a variety of professional development for SETM and technology secondary and post-secondary educators focused on advanced technologies. She earned a B.A. in Chemistry at Agnes Scott College and both a B.S. in Engineering Science and a Ph.D. in Civil Engineering (Environmental) from the University of South Florida, where her research focused on membrane separation science and technologies for water purification. She has over 20 years of experience in developing curricula for engineering and engineering technology for elementary, middle, high school, and post secondary institutions, including colleges of engineering. Dr. Barger has presented at many national conferences including American Association of Engineering Education, National Career Pathways Network, High Impact Technology Exchange, ACTE Vision, League of Innovation and others. Dr. Barger serves on several national panels and advisory boards for technical programs, curriculum and workforce initiatives, including the National Association of Manufacturers Educators' Council. She is a Fellow of the American Society of Engineering Education, a member of Tau Beta Pi and Epsilon Pi Tau honor societies. She is a charter member of both the National Academy and the University of South Florida's Academy of Inventors. Dr. Barger holds a licensed patent and is a licensed Professional Engineer in Florida.

\section{Dr. Richard Gilbert, University of South Florida}

Richard Gilbert is a Professor of Chemical and Biomedical Engineering at the University of South Florida's College of Engineering . Richard is the Co-PI for the grant that supports the NSF designated Center of Excellence for Advanced Technological Education in Florida, FLATE. FLATE, now in its 10 year of operation, addresses curriculum, professional development, and outreach issues to support the creation of Florida's technical workforce. Richard has over 30 years of experience working with the K-14 education community. Other funded efforts include projects for the NIH and the US Department of Education. The latter was for the development of an engineering curriculum for elementary school applications. The former is for development of electric field mediated drug and gene applicators and protocols. This effort has generated over 20 patents and cancer treatment protocols currently in Phase II trials. 


\title{
New Mechatronics Education Initiatives in 2-year Programs
}

\begin{abstract}
The number of associate level degree programs in Mechatronics is growing rapidly across the country. These programs are trying to meet the increasing nationwide need for technicians that can install, maintain, troubleshoot, and service subsystems that often integrate pumps, motors, valves, sensor, and interface software that are responsible for the operation and/or control of manufacturing processes. These technicians are typically identified as mechanical, automation, robotics, and/or mechatronics technicians. These associate degree level programs are also aligning their curriculum with several international, industry valued credentials to best prepare the 2-year mechatronics technicians to be ready for work in the growing number of highly automated facilities across the country. This paper reviews several of these evolving programs; how they have updated electrical and/or mechanical technology programs to include current technology and industry workforce need; how the industry credentials are impacting their programs, students and employers; and their efforts to build capacity by partnering with local high schools to better meet the needs of employers in their communities.
\end{abstract}

\section{Keywords}

Mechatronics, manufacturing, education, technicians, automation, pathways, technical associate degree, 2-year, electromechanical, technician education

\section{Historic Background}

The term "Mechatronics" was first coined by Tetsuro Mori and was a trademark of Yasakawa Electric Corporation, the Japanese company he worked. Yasakawa Electric was involved with consumer products and their initial insertion of microprocessors into their purely mechanical systems marked a beginning of operating and controlling mechanical systems with electronic devices. The development and growth of sensor technologies with their inclusion of electromechanical systems extended and popularized the use of mechatronics as an inclusive term for this discipline. Today, core concepts of controlling a system with electronics and communication technologies is fundamental to mechatronics systems. Mechanical, electrical and electronic communications have continued to evolve at an accelerating rate during recent decades and manifest themselves in mechatronic systems. ${ }^{1-2}$

Any robot also represents its own mechatronic system. The robot has a number of sensors that takes in information (e.g., a signal from a clock, verbal command, etc), processes that input signal to an analog or digital input command. Thee commands are delivered to an analog or digital controller that analyzes the situation based on expected values of these processed input signals. A different set of conditional signals are transferred to final control elements that are 
integrated elements that are integrated into various parts of the robot to allow it to respond (e.g., make a series of movements, pick up an object, etc) with the expectation that this new set of actions will alter the sensors' next response to also meet an expected value(s).

The defense sector has been a leader in developing sophisticated mechatronics sys tems for military applications. Consumers have had relatively simple mechatronic systems (e.g., garage door openers, thermostats, controlled air conditioning, darkness activated lighting, low gas indicator lights in vehicles, and remote-controlled televisions, etc) in their homes for decades. Today, the Internet of Things (IoT) has taken mechatronic systems to the next step and allows us to control a variety of mechatronic devices from a single wireless dashboard like a smart home app on a cellular phone. Today, there are a growing number of sensors, smaller components (electronic, mechanical ad communication), increased sensor sensitivity and speed, robust data collection and analysis tools and a growing number and variety of communication platforms that are all available at lower and lower costs. Designing, building, operating, maintaining, and repairing these systems are task for mechatronic engineers and technicians.

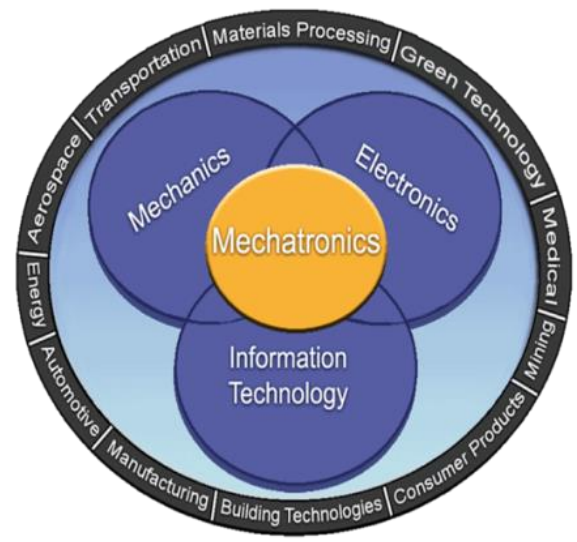

Figure 1. Typical Illustration of Mechatronics

\section{Snapshot of Mechatronics Technician Education}

Unfortunately, there is no official occupation for Mechatronics Technicians in the Department of Labor, Employment and Training Agency (DOL ETA) Standard Occupation Classifications (SOC). The closest job titles currently listed are Robotics Technician (SOC 17-3024.01), Mechanical Engineering Technician (SOC 17-3027.00), Electro-mechanical engineering Technician SOC 17-3024.00). However, Mechatronics Engineer (17-2199.05) has recently been added $^{3-4}$. In addition to the guidance colleges can get from these national occupation descriptions, the U.S. Department of Labor developed a Competency Model for Mechatronics shown in Figure $1^{5}$. The block diagram is surface icon for an in-depth list of competencies at each level moving up the pyramid that can be downloaded from the Career One Stop website in several formats. The yellow layers contain industry specific skills and knowledge and, therefore, provide specific information for mechatronics technicians with associate degree. The lower red levels provide information about fundamental knowledge in mathematics, language arts, and science. The bottom gray level defines employability and workplace skills. The competency model provides detailed information about the skill set that defines this occupation in a linked spreadsheet compiled by the ETA from industry responses. 


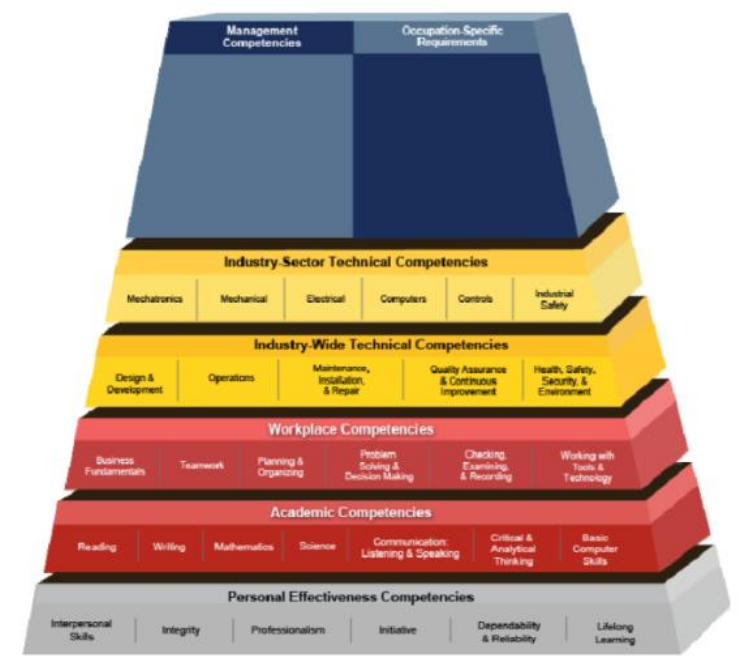

Figure 2. US DOL Mechatronics Competency Model

Two-year technical programs prepare students to become mechatronics technicians and typically include more than 40 credit hours of a 60-90+ credit hour degree plan in technical, hands-on course work at a community or technical college. The degrees can be either Associate of Science or Associate of Applied Science depending on the degree definitions in different states and the institutions themselves. The programs include general education requirements that include fundamental math, language, science, social sciences and humanities courses, as well as core technology courses like electronics, safety, CAD /solid modeling, print reading, tools and instrumentation, and quality. Building on the fundamentals, courses at the second-year level include more electronics, mechanical drives and systems, fluid systems (hydraulic and pneumatics), programmable logic controllers, robotics, instrumentation and controls, and electric motors and capstone (culminating project). A review of over fifty associate level mechatronics programs in the United States revealed that over $90 \%$ of those programs had at least one course in each subject mentioned above as the "second year" courses. Local program "flavor" depends on regional industry needs and is expressed in other related courses that might be required or elective.

The future of mechatronics education is exciting and coming very fast. Many industries, including manufacturers, are rapidly adopting the technologies and communication platforms of Industry 4.0 for their production systems. The new term "Industry 4.0 " was coined to capture the growing integration of cyberphysical systems, cloud computing, big data with sophisticated automated and autonomous systems. Integrating communications and artificial intelligence (AI) between the equipment and the industry's business enterprise system results in what is now being called a "smart factory". Because these technologies are already proven to be time-saving and efficiency-enhancing, industries are rapidly adopting and implementing these technologies. Colleges and universities will have to keep pace with this trend and graduate students who understand the depth and breadth of communications layers as well as the intricacies of the technology itself.

\section{Example Programs}


There are a number of very good and mature Associate Degree Mechatronics programs as well as several new and emerging programs across the country. This section will briefly review these. A generic/topical program outline can be found in the appendix of this paper.

Central Community College (CCC) is a multi-campus community college serving a 25-county area in central Nebraska (approximately 14,000 square miles) with a population of more than 300,000. The Mechatronics program (62-64 credit hours) has been in place for over 15 years and offers 2 course sequence specializations: Electromechanical/Mechatronics and Mechatronics Process Instrumentation and Control. CCC also offers four credit certificates in Automation, Control Systems, Fluid Power and Industrial Technology that are 12-14 credits of technical courses that are part of the Mechatronics degree plan.

(http://www.cccneb.edu/Home/)

The College of Lake County (CLC) is developing a new mechatronics associate degree program based on industry requesting graduates with more experience in automated systems. The new degree is currently a 24-hour certificate under a strong Mechanical Engineering Technology Degree program. The new Mechatronics Degree will prepare students for the Siemens Mechatronics Certifications. CLC is working with Ann Arundel CC and Florida State College at Jacksonville (FSCJ) to develop a low cost mechatronics trainer for high schools and providing these with professional development to schools in their regions. CLC is located in northeast Illinois close to Lake Michigan. (http://www.clcillinois.edu/)

Hagerstown Community College (HCC) in Hagerstown, MD offers a newly updated Advanced Manufacturing Systems AAS degree and related shorter college certificate. HCC serves a variety of traditional manufacturing companies in a long-time manufacturing area in rural Maryland. Companies in this region are now adding more automated and advanced manufacturing technologies and the program is adding new motors and controls systems and integrated components communications. (http://hagerstowncc.edu)

Hillsborough Community College (HCC) located in Tampa, Florida offers a 30-credit hour Mechatronics college credit certificate that is housed within its Engineering Technology Associate Degree ${ }^{6}$. This program has over one hundred full and part-time students enrolled. Its Engineering Technology Core courses are aligned to the Manufacturing Skills Standard Council Certified Technician (MSSC-CPT) and the courses in the Mechatronics certificate are aligned to PMMI Mechatronics certification. (https://www.hccfl.edu/)

Motlow State Community College (MSCC) located in south middle Tennessee and offers a 63-credit hour Associate Degree. Motlow's graduates are prepared for the Siemens Mechatronics certifications. Motlow State serves as the first official Siemens Training Center in the United States making this certification more accessible to mechatronics students across the United States. (https://www.mscc.edu/)

Piedmont Virginia Community College (PVCC), located in Charlottesville, Virginia has a new focus on Mechatronics in a college career certificate within its Electronics and Computer 
Technology Associate Degree. The career certificate is aligned to the Manufacturing Technician Level 1 (Manufacturing Skills Institute) and the Certified Mechatronic Systems Assistant (Siemens). (https://www.pvcc.edu/)

South Central College (SCC) is located in southern Minnesota and serves a wide range of industry including the packaging and agricultural sectors in that region. To best support these industry, South Central has developed portable trainers and remote access equipment to provide remote and working students access to this educational program (http://southcentral.edu/)

Virginia Western Community College (VWCC) is home to another well-established Mechatronics Associate Degree program that has had a big regional economic impact in and around Roanoke, Virginia. This program offers a college certificate as well as the degree and uses the college's Fab Lab to support student projects in all mechatronics courses. VWCC is also aligned to the Siemens certification and has help teachers in nearby manufacturing high school programs become certified as well as their own students. (http://virginiawestern.edu/ )

\section{Pathways to Bachelor's Degrees}

There are a number of 4-year programs in Mechatronics Technology Engineering or General Engineering Technology that graduates of these example programs, among others, can easily continue their programs of study. Purdue Northwest University (formally, Calumet) and Texas A \& M University both have strong bachelor's degree programs that accept 2-year mechatronics graduates. Graduates of Florida's Engineering Technology Associate Degree in Advanced Manufacturing (Mechatronics) will soon be able to use a statewide articulation to Daytona State College (DSC) to complete a bachelor's degree in Engineering Technology with mechatronics focus. The DSC program is a hybrid program offering flexibility for all students, especially working students. All courses in the program are offered online and all labs can be completed on campus but also have several off-campus options to complete. Additionally, there are a growing number of Mechatronics, Mechatronics Engineering or Mechatronics tracts in traditional mechanical, general or electrical engineering programs which may offer transfer opportunities for 2-year mechatronics students.

\section{Online Communities}

In many cases, the associate programs have a single full-time faculty, a part-time lab technician, and possibly a couple of adjunct faculty. Although passionate about teaching as well as their technology, they often work in an isolated environment. In order to help keep these educators up to date with technology, pedagogy, issues and trends, the Mechatronics Community Exchange (MCE) was formed as a "grassroots" online community that provides support to 2-year faculty involved in this technology the opportunity to share resources among mechatronics faculty and educators. The college faculty, program directors, deans, etc. discuss various topics that include new equipment, lab layouts, student projects, math requirements, online resources, hybrid and remote teaching, student recruitment and many others. The MCE meets online several times per semester web-based meeting platform and the topic and agenda for each meeting is determined by the group. These sessions are not webinars per se, but rather sharing sessions particular topics. 
Occasionally an invited expert on a topic of interest joins the meeting to share his/her expertise and answer questions in the small group. The community is hosted and supported by FLATE, the Florida Advanced Technological Education Center of Excellence NSF ATE (\#1204751), an NSF ATE Regional Center of Excellence, the PACE-ME NSF ATE project at Virginia Western Community College (NSF ATE \#1400571) and the CollaborATE ATE project at the College of Lake County (NSF ATE \#1601172). You can find out more online on the MCE webpage.

There is also a new and growing community of educators who have started a group with regular meetings, forums and webinars to share information and to build their bachelors level educational programs. This portal is sponsored and hosted by Quanser and National Instruments. Mechatronics Education (www.mechatronicseducation.org) is an online resource portal and forum let by mechatronics faculty in universities and baccalaureate degree offering colleges.

\section{Summary}

More new mechatronics programs are being started across the country to help address the national skills gap as more industry and industry sectors implement robotic and automated systems. Many of these emerging mechatronics associate degree programs are aligning themselves to industry validated national credentials to best prepare their students for work in high wage and in-demand jobs. These national credentials help keep the programs up-to-date and add national and international standards to the local industry needs. The national and international credentials also provide students and working technicians defined portable skillsets that industry across the country need. These mechatronics programs at all levels are the natural place for emerging technologies and trends and many are beginning to integrate Industry 4.0 concepts and the Internet of Things (IoT) into their programs.

\section{References}

1. Dixit U.S., Hazarika M., Davim J.P. (2017) History of Mechatronics. In: A Brief History of Mechanical Engineering. Materials Forming, Machining and Tribology. Springer, Cham

2. Bishop, Robert H, A History of Mechatronics, CRC Press Taylor \& Francis Group, 2006

3. Bureau of Labor Statistics https://www.bls.gov/soc/

4. O*NET Resource Center https://www.onetcenter.org/

5. DoL Competency Home https://www.careeronestop.org/CompetencyModel/competencymodels/mechatronics.aspx

6. Barger, Marilyn; Gilbert, Richard; Florida's Engineering Technology Associate of Science Degree Program: A Model for Technical Workforce STEM Based Education, Journal of Engineering Technology, Spring

\section{Appendix}

Typical 2-year Mechatronics Degree (60-68 credit hours)

\begin{tabular}{|l|l|l|}
\hline \multicolumn{2}{|l|}{ General Education: 15-18 credits (includes college math/algebra and science) } \\
\hline Electronics 1 & Applied Robotics & Quality Systems and Measurements \\
\hline Hydraulics/Pneumatics & Automated Systems & Advanced/Industrial Electronics \\
\hline Programmable Logic Controllers & Motors and Controls & Safety \\
\hline
\end{tabular}




\begin{tabular}{|l|l|l|}
\hline Mechanical Systems & Computed aided drafting & Lean Manufacturing \\
\hline Internship/work experience & Possible electives & \\
\hline
\end{tabular}

